\title{
The dilemma of accuracy in IUCN Red List categories, as exemplified by hawksbill turtles Eretmochelys imbricata
}

\author{
Grahame J. W. Webb ${ }^{1,2, *}$ \\ ${ }^{1}$ Wildlife Management International, PO Box 530, Sanderson, Northern Territory 0813, Australia \\ ${ }^{2}$ School of Environmental Research, Charles Darwin University, Darwin, Northern Territory 0909, Australia
}

\begin{abstract}
Since 1963 the International Union for Conservation of Nature (IUCN) Red List has provided the world with a credible and effective call to action for preventing species extinction. However, the criteria for assigning categories of threat (e.g. 'critically endangered,' 'endangered,' 'vulnerable'), particularly the 'decline criteria' (Criteria A), often exaggerate the real risks of extinction and are thus not accurate. This is exemplified here by hawksbill turtles Eretmochelys imbricata, but the problem is more widespread. There is an expectation by scientists that these accuracy problems will be rectified, yet this is by no means a minor adjustment for the Red List to make, because the Red List itself operates under significant constraints. The Red List is expected to meet the requirements of scientists and advocates, to be consistent with historical precedents, to pursue new directions at the biodiversity level, to meet the often conflicting views and values of diverse IUCN members, and still has to weather the stormy politics of conservation. Proposed changes to listing procedures would need to be scientifically justified, politically acceptable and as benign as possible to ongoing processes, such as biodiversity monitoring. The decline criteria are perhaps the most problematic, and these are examined in more detail here. A fundamental weakness is that they respond more to the challenge of reinstating historical abundance than to avoiding global extinction per se. This could potentially be overcome by using the current decline criteria to make an objective first stage determination based solely on decline (e.g. 'critically declined'), thereby overcoming almost all scientific objections concerning accuracy. A second-stage assessment could then examine the significance of that decline, in terms of allocating species to the existing extinction risk categories or retaining them as critically declined. There is an increasing conservation and humanitarian expectation that the IUCN, through the Red List, will become more involved with species that are critically declined but well-buffered against global extinction. To use global extinction as the gatekeeper to the IUCN's involvement in conservation issues today is difficult to justify.
\end{abstract}

KEY WORDS: International Union for Conservation of Nature $\cdot$ IUCN $\cdot$ Red List $\cdot$ Hawksbill turtle Resale or republication not permitted without written consent of the publisher

\section{INTRODUCTION}

The International Union for Conservation of Nature (IUCN) was founded in 1948, as the International Union for the Protection of Nature (IUPN). IUPN members comprised government and non-government environmental organisations (NGOs) committed to protecting wildlife, environments and natural resources. In 1956 the IUPN changed its name to the International Union for the Conservation of Nature and
Natural Resources (IUCN). In 1990, the term 'IUCNWorld Conservation Union' was adopted to better describe what the IUCN had become: a much larger organisation, capable of exerting more political influence. In 2008, the descriptor 'World Conservation Union' was abandoned, as was any reference to 'natural resources.'

One of the international flagships of the IUCN is the IUCN Red List of Threatened Species. The Red List is a scientifically based call to action for preventing the 
extinction of wildlife around the world (Rabb 1996). It has been available in different forms since 1963 (Scott et al. 1987, IUCN 2007a) and showcases the formidable scientific and technical capacity of the IUCN in the collection and analysis of vast amounts of information on the changing status of the world's wild plants and animals. The provision of status data to the Red List relies on a massive voluntary effort by global scientists; thus, maintenance of the IUCN's scientific credibility is fundamental to its ability to sustain that cooperation and keep status information flowing.

Within the IUCN, the Species Survival Commission (SSC) and IUCN Species Program (SP) compile the Red List. SSC Specialist Groups (SGs), comprised of some 7000+ volunteers, provide the data. SGs were involved in evaluating and testing the current generation of Red List Criteria in the early 1990s (Mace \& Landy 1991, Mace et al. 1992, IUCN 1993, 2001, Mace \& Stuart 1994, Baillie \& Groombridge 1996) and carried out virtually all Red List assessments before after that date. Within SGs, the responsibility for undertaking Red List assessments usually falls to a subset of SG members familiar with the status of whatever species is being assessed. Draft assessments are typically reviewed and approved by SG members and/or chairperson/s, before being forwarded to the Red List Authority, where a second round of reviews takes place before the findings are accepted or rejected.

\section{PROBLEMS WITH ACCURACY}

The IUCN Criteria and protocols for deciding which extinction risk category ('critically endangered,' 'endangered,' 'vulnerable,' etc.) should be assigned to which species, appear reasonably rigid. But when tested, different biologists presented with identical data sets on the status of 13 species of wildlife assigned extinction risk categories ranging from not threatened (least concern) to critically endangered for the same species (Regan et al. 2005). There were, thus, problems with both accuracy and precision. Variability in the willingness of assessors to commit themselves to inferences about a particular parameter given the available information was the key factor involved in different assessors reaching different conclusions.

Within the SSC Marine Turtle Specialist Group (MTSG), there has long been a tendency to treat inference in a biased way, accepting as fact any inference that populations are declining, but demanding high levels of scientific proof before accepting any evidence they are increasing (Mrosovsky 2002, 2003). Not surprisingly, there are many concerns about Red List assessments and the categories of extinction risk assigned to different sea turtle species (Mrosovsky 1983, 1997, 1998, 2000, 2002, 2003, Lapointe 1997, Webb \& Carrillo 2000, Seminoff 2004a,b, Broderick et al. 2006, Godfrey \& Godley 2008 this Theme Section, Seminoff \& Shanker 2008). Indeed, of the 29354 animal species listed in the 2007 Red List (IUCN 2007a, their Table3a), and of some 40200 species assessed ('Information sources and quality: marine taxa' in IUCN 2007a), only with marine turtles have formal appeals been made and referred to the IUCN-SSC Standards and Petitions Working Group (SPWG) for resolution (IUCN 2007b). Two of the marine turtle appeals were upheld and 2 were partly upheld.

The SPWG assesses whether the Red List Criteria have been applied in a technically correct way, and has no mandate to examine whether the final risk categories assigned are realistic. If the criteria are deemed by the SPWG to have been applied in a technically correct way, but the extinction risk categories derived are still wildly inconsistent with known risks of global extinction, then the only conclusion that can be drawn is that the criteria are flawed. There are obvious difficulties in determining the definitive risk of extinction, because it requires extinctions to occur. Yet with vertebrates at least, impending extinction stimulates serious conservation actions, which mitigate against extinction occurring. With invertebrates, the knowledge base is so poor that species are going extinct before being described, let alone having their status assessed (Wilson 1992, Brown \& Lomolino 1998). Yet sometimes inaccuracies are blatantly obvious (Webb \& Carrillo 2000, Seminoff 2004a,b, Rice \& Legacé 2007, Godfrey \& Godley 2008, Seminoff \& Shanker 2008) and here hawksbill sea turtles Eretmochelys imbricata provide an example.

The status of the global population of hawksbill turtles was changed from endangered to critically endangered in the 1996 IUCN Red List of Threatened Species (Baillie \& Groombridge 1996), based on the 1994 Version 2.3 of the new Red List Criteria (IUCN 1994). The definition of extinct was: 'when there is no reasonable doubt that the last individual (in the world) has died.' Critically endangered was defined as: 'facing an extremely high risk of extinction in the wild in the immediate future,' but with the technical qualification: 'as defined by any of the criteria (A to E).' (Baillie \& Groombridge 1996, p. 63)

As emphasised by others (Webb \& Carrillo 2000, Mrosovsky 2003, Godfrey \& Godley 2008, Seminoff \& Shanker 2008), it is a measure of IUCN's credibility that when it assigns a species such as Eretmochelys imbricata a label such as critically endangered, the highest level of threat, most observers accept it as an IUCN 'Red Alert' for immediate conservation action scientific justification for extreme measures to be 
implemented to prevent impending extinction. Such measures might include strict protection of all remaining global wild individuals or even captive breeding to ensure the unique genetic stock is not lost. Yet the Red List Authority (RLA) consistently warns against interpreting the results of their assessments in such a direct way. It advises (see '10. Threats and Priorities' in IUCN 1994) that their assessments should not be used to prescribe and prioritise conservation actions, and that they are policy relevant rather than policy prescriptive (Brackett 2004). Yet when Red List assessments are extended to regional and national levels, their impact on policy is both intended and unavoidable (Miller et al. 2007).

The IUCN thus places serious but confusing limitations on the veracity of their own Red List assessments. These technical limitations tend to be unknown outside the IUCN and are thus ignored in the public and political arenas. The category in which a species is listed on the IUCN Red List is continually used to influence policy (Possingham et al. 2002), despite being technically incapable of fulfilling that role.

The 1996 assessment of Eretmochelys imbricata was made by the MTSG, but apparently without comment and review by the MTSG membership as a whole (Mrosovsky 2003). The assessment was provided to the RLA without supporting data and appears to have been rather unquestioningly accepted and published. This was a time of transition to the new Red List assessment system and so perhaps many SGs were not as diligent as they should have been about such issues. Nevertheless, NGOs acted quickly on the Red List's critically endangered label for hawksbills. For example, World Wildlife Fund (WWF) for a time listed them as one of the 'Top 10' most critically endangered wildlife species in the world! A hindsight justification for the 1996 assessment was provided 3 years later (Meylan \& Donnelly 1999).

Coincidently, the 1996 upgrading to critically endangered occurred at a strategically important time for the MTSG. Cuba was preparing a proposal to the Convention on International Trade in Endangered Species of Wild Fauna and Flora (CITES) to allow limited international trade in Eretmochelys imbricata (ROC 1998, Mrosovsky 2002, 2003, Webb \& Manolis 2002), which was opposed on principle by many MTSG members of the day, including those who did the Red List assessment. The IUCN critically endangered label was used very effectively to lobby the Parties to CITES against Cuba's proposal at the 10th Conference of Parties to CITES (CITES CoP10) in 1997 (ROC 1998) and the 11th Conference of the Parties to CITES (CITES CoP11) in 2000 (ROC 2000). The Cuban proposal failed by a small margin of votes, despite E. imbricata being abundant in Cuban waters and Cuba arguably developing a model conservation and management program based on limited sustainable use (Carrillo et al. 1998c, 1999, ROC 1998, Fleming 2001, Webb 2002), consistent with IUCN's mission and with the Objectives (Article 1) of the Convention on Biological Diversity (CBD), but not with the views of the MTSG. The 1996 Red List determination, despite being inaccurate, served a powerful political and advocacy purpose, and was definitely policy prescriptive.

In reality, the global population of Eretmochelys imbricata was not at risk of becoming extinct in 1996 and nor is it today. There were no realistic scenarios through which the last wild E. imbricata could go extinct, even in the long-term future (Meylan \& Donnelly 1999, Webb \& Carrillo 2000). As emphasised by Godfrey \& Godley (2008) and Seminoff \& Shanker (2008), despite a diversity of conservation problems in parts of their range, including severe depletion, $E$. imbricata and other marine turtle species are better buffered against global extinction than perhaps most species. They have very wide distributions and inhabit the sea, where extinctions are rare relative to terrestrial and freshwater environments (IUCN 2007a, Table 3a). Hawksbills were already listed in Appendix I of CITES and since 1993, international trade, previously considered the major threat to the species, had ceased. The levels of trade detected since 1993 are trivial in comparison to those before 1993 (Milliken \& Tokunaga 1987, CITES 2008). By 1996, E. imbricata had been protected in many countries for many years (Groombridge \& Luxmoore 1989), which had resulted in some populations being abundant and some increasing in abundance rapidly (ROC 1998, 2000, Webb \& Carrillo 2000, CITES 2002) (Table 1). The global wild population in 1996 may well have been in the millions of individuals (Webb \& Carrillo 2000), even if this did reflect an $80 \%$ reduction in the global population size 3 generations and, thus, $100+$ yr ago.

The IUCN term critically endangered thus grossly exaggerated the real risk of global extinction for Eretmochelys imbricata in 1996. The detailed SPWG review found that Criteria A1 (the 'decline criteria' for past abundance) had been applied correctly. Erring on the side of caution, it was reasonable to accept that the wild population was $80 \%$ declined in 1996 relative to 3 generations beforehand. The SPWG thus confirmed that an $80 \%$ decline in the world population was not an accurate indicator of a high risk of global extinction. Criteria A1 were thus flawed in the case of $E$. inbricata, as suspected for other marine turtle species (Mrosovsky 2003, Seminoff 2004b, Broderick et al. 2006, Godfrey \& Godley 2008, Seminoff \& Shanker 2008), crocodilians (Webb \& Carrillo 2000), fish (Rice \& Legacé 2007) and perhaps a wide range of other species. 
Table 1. Eretmochelys imbricata. Sample nest counts at 7 nesting areas in the Caribbean in 2001 (CITES 2002). When the counts within each area for 2001 ( $\mathrm{n}=6089$ nests) are adjusted by the rates of increase, the sample population as a single Caribbean unit was predicted as increasing at $20.0 \%\left(\mathrm{n}=1220\right.$ nests) $\mathrm{yr}^{-1}$ in 2001 . These data were available when the Standards and Petitions Working Group (SPWG) upheld the 1996 determination of critically endangered for the global population of E. imbricata. The SPWG accepted that a historical decline of more than $80 \%$ (Criteria A1 in Versions 2.3) may still have occurred (despite the current rate of increase) but rejected the claim that a future decline of $80 \%$ (Criteria A2 in Version 2.3) was expected. Mean change $\mathrm{yr}^{-1}(\mathrm{MC})$ was calculated from the intrinsic rate of population increase. Gaps indicate no data available

\begin{tabular}{|c|c|c|c|c|c|c|c|}
\hline Year & $\begin{array}{l}\text { Yucatan } \\
\text { Peninsula }\end{array}$ & $\begin{array}{l}\text { Buck } \\
\text { Island }\end{array}$ & $\begin{array}{c}\text { Jumby } \\
\text { Bay }\end{array}$ & $\begin{array}{l}\text { Mona } \\
\text { Island }\end{array}$ & $\begin{array}{c}\text { Doce } \\
\text { Leguas }\end{array}$ & Tortuguero & Barbados \\
\hline 1987 & & 73 & 103 & & & 10 & \\
\hline 1988 & & 126 & 154 & & & 12 & \\
\hline 1989 & & 116 & 129 & 126 & & 6 & \\
\hline 1990 & 826 & 79 & 77 & 196 & & 3 & \\
\hline 1991 & 1053 & 119 & 139 & $142^{\mathrm{a}}$ & & 1 & \\
\hline 1992 & 1282 & 88 & 114 & $142^{\mathrm{a}}$ & & 4 & \\
\hline 1993 & 1891 & 101 & 107 & & & 0 & \\
\hline 1994 & 2563 & 118 & 109 & 308 & & 4 & \\
\hline 1995 & 3690 & 135 & 126 & $157^{a}$ & & 2 & \\
\hline 1996 & 4522 & 114 & 82 & 354 & & 12 & \\
\hline 1997 & 2671 & 85 & 94 & 475 & 34 & 10 & 328 \\
\hline 1998 & 4701 & 121 & 117 & 503 & 32 & 9 & 515 \\
\hline 1999 & 6395 & 94 & 120 & 511 & 70 & 12 & 717 \\
\hline 2000 & $5746^{\mathrm{a}}$ & 65 & 113 & 541 & 45 & 9 & 807 \\
\hline 2001 & 3969 & 143 & 159 & 549 & 72 & 18 & 1179 \\
\hline $\mathrm{MC}$ & $+18.2 \%$ & Stable & Stable & $+12.6 \%$ & $+20.2 \%$ & Stable $^{\mathrm{b}}$ & $+35.1 \%$ \\
\hline Upper CI (\%) & 25.5 & 2.7 & 2.1 & 15.7 & 61.2 & 2.5 & 48.9 \\
\hline Lower CI (\%) & 11.3 & -5.0 & -3.5 & 9.5 & -10.3 & -6.5 & 22.5 \\
\hline $\mathrm{R}^{2}$ & 0.79 & 0.04 & 0.03 & 0.94 & 0.57 & 0.03 & 0.97 \\
\hline
\end{tabular}

\section{EXAGGERATING RISKS OF EXTINCTION}

Overstating the risks of wildlife becoming extinct tends to be justified on the basis of the Precautionary Principle (Cooney 2004): better to overstate than understate risks. But in science, precaution means avoiding speculative conclusions drawn improperly from data. For most scientists, deliberate and gross exaggeration amounts to deception, which is considered unprofessional, unethical and shortsighted. If it results in attention and resources being directed away from species genuinely at risk of extinction, in favour of charismatic species that are not, it is considered counterproductive to the general goals of biodiversity conservation (Webb 2000, Godfrey \& Godley 2008, Seminoff \& Shanker 2008). If some of the Red List Criteria are flawed in the direction of grossly exaggerating extinction risks, then MTSG scientists volunteering their skills to the IUCN are justified in demanding corrective action be taken and they are correct in voicing their concerns about the impact these inaccuracies have on IUCN credibility (Mrosovsky 1997).

Yet scientific precaution often clashes with the goals of advocacy, with which many IUCN member organisations are involved. Exaggerating risks of extinction, whether ethical or not (Shrader-Frechette \& McCoy 1999), is an effective political strategy for achieving conservation outcomes and the end justifies the means in the eyes of many (Mrosovsky 1983, 2002, 2003). Labels like critically endangered stimulate political action to abate threats (Possingham et al. 2002) and stimulate the flow of resources to the people, programs and organisations conserving species. As SG members doing Red List assessments are often beneficiaries of that funding, the potential for self-serving assessments has long been recognised. So although exaggeration may not rest easily with many scientists concerned about environmental issues, others apparently do not care:

Science is not going to be the deciding factor, or even a major player in the debate but rather the values, opinions, and politics of the players. Scientists will increasingly find that the issues will not be argued on their merits, and that the introduction of scientific evidence will simply be ignored. (Salzman 1995, p. 709)

\section{CORRECTIVE ACTION}

The response of the IUCN to claims that the Red List exaggerates risks of extinction was to review the crite- 
ria (IUCN/SSC Criteria Review Working Group 1999). This resulted in some decline thresholds being marginally altered, but little more of substance. More telling were the editorial changes made to the definitions of the Red List extinction risk categories. They further emphasised the sanctity of process (the criteria) over the accuracy of the product (extinction risk categories). For example, the definition of critically endangered became:

When the best available evidence indicates that it meets any of the Criteria A to E for Critically Endangered (see Section V), and it is therefore considered to be facing an extremely high risk of extinction in the wild. (IUCN 2001, p. 16)

Such subtle changes helped absolve the hard-working Red List personnel from responsibility for errors, but did little to overcome the problems created by inaccurate assessments at the level of implementing conservation and management programs (Godfrey \& Godley 2008, Seminoff \& Shanker 2008).

By limiting the indices of extinction risk to Criteria A to $E$, the Red List achieves standardisation of the process across different species, which is purported to have analytical advantages (Miller et al. 2007). However, if these advantages come at a cost of declining precision and accuracy, undermining the IUCN's scientific credibility, and constraining innovative approaches to management, such as in Cuba's program, the case for closer scrutiny is a compelling one. What that scrutiny reveals is that the Red List Criteria constitute a theoretical model of extinction risk for all plants and animals - a hypothesis rather than an established truth. The expectation that the criteria will accurately discern the risk of global extinction, in isolation of any or all other information or extenuating circumstances, requires a significant act of faith in them. It amounts to accepting a scientifically based dogma in a field where the majority of scientists perceive scientific method as being a dynamic process, in which accuracy and precision can be improved continually as progress is made from corrected error to corrected error.

\section{THE CHANGING CONTEXT OF THE RED LIST}

Correcting the Red List Criteria to improve accuracy and precision is obviously not a simple matter neither technically nor politically. Changes may well require support from IUCN staff, members, committees and programs, and it does not automatically follow that such support would be forthcoming. This conclusion seems obvious if one tracks the way in which the context of global wildlife conservation, within which the Red List is firmly embedded, has changed over time, and how at least some problematic areas in the Red List Criteria were introduced deliberately.

When the IUCN Red List was first launched in 1963, it was directed mainly at scientists concerned about widespread species extinctions (Scott et al. 1987). Keeping abreast of international conservation at that time was difficult, because global travel was time-consuming and expensive, and communication, the media and computing were all far less efficient than they are today. A call to action for conservation meant encouraging governments rather than NGOs to take action. Game management and protected area management were well established, but not endangered species or biodiversity legislation. Species dangerous to people, or which competed with people, were considered pests, with bounties and eradication programs commonplace. Within this context the IUCN Red List was timely, conceptually innovative and effective.

The whole concept of wildlife species needing to be 'saved' from extinction caught public attention. The Red List focus on global rather than local or national extinction provided even more compelling reasons to act quickly. Scientists associated with the IUCN could use any information to identify endangered species because judgements by scientists were largely accepted as a truth in the early 1960s. The Red List provided credible evidence, assembled by credible people, upon which decisions and policy could be based. International trade was identified as a serious threatening factor, which ultimately led to CITES in 1973.

During the 1970s and 1980s public membership to conservation NGOs expanded greatly, and with financial and political resources, their influence expanded. Calls to action for conservation were increasingly directed to NGOs as they became more effective at winning the public and political support needed for change. SGs expanded, but with biologists and committed conservationists rather than with experienced wildlife managers. Protectionism, with opposition to the consumptive uses of wildlife, became a policy platform of many NGOs and SGs. As scientific evidence was increasingly found on all sides of all arguments, scientific credibility waned. The Red List adapted to the new circumstances (Scott et al. 1987), with scientific content retained, but the format more popularised ('Improving the Red List as a conservation tool' in Baillie \& Groombridge 1996). The focus on species facing extinction at the global level was retained (Scott et al. 1987).

During the 1980s and 1990s serious challenges to the 'protectionist-only' approach to wildlife conservation appeared. For example, with marine turtles (Fosdick \& Fosdick 1994, Mrosovsky 1983, 2000) and crocodiles (Webb et al. 1984, Ross 1998, Hutton \& Webb 2002, 
2003, Hutton et al. 2002), strong cases for conservation programs to include sustainable consumptive use and trade were made. They were typically opposed by NGOs and SGs. The decision to develop more rigorous Red List Criteria (Mace \& Landy 1991) was based partly on overcoming the ease with which species could be listed as an added tier of protection - the 'ad hoc process of including species on the Red List' ('Establishment of Red List Authorities' in IUCN 2007a). For similar reasons, CITES developed more rigorous protocols for listing species on their Appendices (Resolution Conf. 9.24). Concerns about biodiversity conservation were mounting and the Red List was uniquely positioned to quantify trends if more objective criteria for listing could be developed.

\section{EVOLVING ‘DECLINE' CRITERIA}

When the new draft Red List Criteria were completed and circulated for comment (Version 2.2; Mace \& Stuart 1994), it was unclear whether widely distributed species such as marine turtles, many marine fish and some crocodilians would continue to be listed. Few had restricted distributions or small population sizes. If they were eligible for continued listing in the Red List, it would depend largely on satisfying the 'decline criteria' (Criteria A). But even here there were problems (IUCN 1995).

The thresholds for significant decline initially proposed in the draft criteria (Version 2.2; Mace \& Stuart 1994) were an $80+\%$ reduction in abundance for critically endangered and a $50+\%$ reduction for endangered. The time frame over which these reductions occurred was defined as 'during the last 10 years or 3 generations for which data are available'. There were few historical data from 3 generations ago, and within the last 10 years, in response to conservation action, survey data for an increasing number of populations were demonstrating stable or expanding populations. That marine turtles might not meet the decline criteria concerned the MTSG:

\footnotetext{
Marine turtles may be incorrectly assigned to status categories by IUCN, CITES and other treaties either because the criteria are inappropriate for marine turtles or because we have insufficient data for analysis. (IUCN 1995, p. 18)
}

Version 2.2 of the Red List Criteria ran the gauntlet of review by SGs and others and was revised with 'changes as a result of comments from IUCN members ('2001 Categories and Criteria', in IUCN 2007a). An amended version (Version 2.3) was finally adopted by the IUCN Council in December 1994, ending years of development and consultation, and starting a new phase in Red List history. However, some important editorial changes had been made to the decline criteria (Criteria A).

The condition in Criteria A, 'for which data are available,' had been replaced with 'whichever is the longer.' For marine turtles and crocodilians, with generation times that may reach 40 to $50 \mathrm{yr}$, this meant that the IUCN would not assess extinction risk in the future on the basis of current trends in the wild population, where an increasing body of hard scientific data was accumulating, but rather on the presumed abundance 3 generations previous, which meant $100+$ yr for some species. Few, if any scientific data, for any species, were available from so long ago. Although this compromise may have suited some players, it was obviously flawed, and has created many of the accuracy problems of concern today. For example:

(1) Whether a population is increasing, decreasing or stable now is fundamental to the probability of it going extinct in the future and critical to the ability to allocate scarce resources to conservation priorities. 'Whichever is the longer,' adopted in Version 2.3, relegated the role of current scientific survey results to establishing a single reference point, against which highly imprecise and inaccurate data on historical abundance, often no more than guesswork, could be compared.

(2) The change shifted the focus of the Red List from the problem of avoiding global extinction to the challenge of re-establishing historical abundance. This challenge was exacerbated initially by Criteria A, containing no mechanism for assessing whether it was even possible to achieve historical abundance, due to factors such as habitat loss over 3 generations. In the current Criteria (Version 3.1) this oversight has been addressed in Criteria A1 through adding: 'where the causes of the reduction are clearly reversible' (IUCN 2001). However, Criteria A2 (Version 3.1) now creates a catchall: 'where the reduction or its causes may not have ceased or may not be understood or may not be reversible.'

(3) The shift in focus to reinstating historical abundance can be exemplified by a simple example. If a species had been reduced to $5 \%$ of its historical abundance, which is common with crocodilians (Ross 1998, Webb 2002), investing in conservation action that increased the population by $300 \%$ (to $20 \%$ of former abundance), would make no difference to the critically endangered label. Yet it may have averted the threat of extinction per se. A $900 \%$ increase (to $50 \%$ of former abundance) would still leave the species endangered and a $1500 \%$ increase, vulnerable. Only when abundance 3 generations ago was approached to within $20 \%$, would the IUCN deem the species to be no longer threatened with extinction. 
This difficulty is exacerbated in marine turtles, where status is usually measured by counting nests, and thus given the long ages to maturity, a significant time lag exists between a population recovering and the recovery being detected (Seminoff \& Shanker 2008). It also helps explain the ratchet bias in Red Listing, because once species are listed it is incredibly difficult to get them off, regardless of improved status.

(4) If historical abundance is itself overestimated by a mere $20 \%$, no amount of conservation action can ever remove a species from the Red List. The guidelines for estimating historical abundance ('observed, estimated, inferred or suspected,' IUCN 1994), although matched to the poor quality of information available, cannot be expected to be accurate to within $20 \%$. In the early 1980 s the recovering population of saltwater crocodiles Crocodylus porosus in northern Australia was considered to be 1 to $2 \%$ of former abundance. Detailed research on historical abundance and harvest levels (Webb et al. 1984) later indicated it was really 40 to $50 \%$ (Webb 2002) and that inferred and suspected historical abundance had been overestimated by hundreds of percent. In the case of Eretmochelys imbricata in the Caribbean, his-

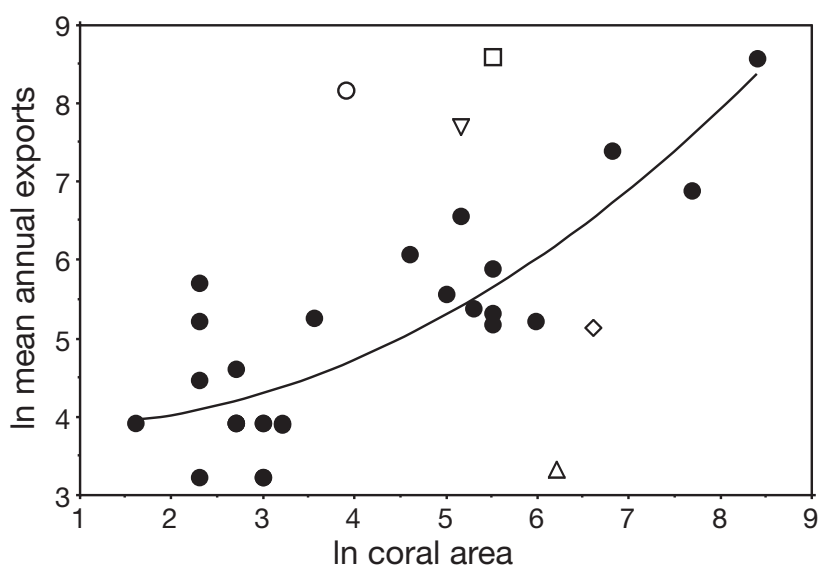

Fig. 1. Eretmochelys imbricata. Relationship between mean annual shell exports to Japan (ln kg) (1973-83) and area (ln $\mathrm{km}^{2}$ ) of shallow water coral reef in 32 geopolitical units in the Caribbean. Data are from Groombridge \& Luxmoore (1989) and ROC (2000; based on Groombridge 1992, NOAA 1999, WCMC 1999). Mexico was excluded as trade was banned in 1973, and Honduras and Nicaragua were combined as a single unit to match the available trade data (see Groombridge \& Luxmoore 1989). 27 units from which the polynominal regression was derived $\left(\mathrm{R}^{2}=0.72, \mathrm{p}<0.0001, \mathrm{n}=27\right) ; 5$ sets of data are overlapped. A linear relationship is significant for all points $\left(R^{2}=0.40, p<0.0001, n=32\right)$. Open symbols indicate nations with significant trade in shell derived in other countries ( $\nabla$ : Haiti; O: Cayman Islands; $\square$ : Panama) or where extensive domestic use and trade through other countries was involved $(\diamond$ : Venezuela; $\Delta$ : Colombia) torical abundance, levels of historical trade and areas of habitat can and should be broadly correlated (Fig. 1). Meylan \& Donnelly (1999) speculated that 900 nesting female $E$. imbricata were taken per night on a beach in Panama as part of a commercial harvest. Although this beach was known to support high levels of nesting, and Panama was a regional trade centre for E. imbricata shell plates from other countries, this level of harvest, as an index of population size, is not consistent with trade levels (Groombridge \& Luxmoore 1989), the availability of habitat (Fig. 1), nor with $E$. imbricata nesting densities anywhere else in the world (Meylan \& Donnelly 1999). It may thus be overestimated by hundreds of percent.

(5) As correctly pointed out by Mrosovsky (2003), as the historical reference point for decline moves forward with the passage of time and eventually reaches the period of peak decline, a species would appear to be superabundant, with no risk of extinction, even if population size and structure had remained stable.

(6) The fact that a species can simultaneously be considered critically endangered on the past decline criteria (Criteria A1, A2 in Version 3.1) and not be considered to be in danger of becoming extinct in the next 10 yr or 3 generations (Criteria A3, A4), is obviously illogical (Mrosovsky 2003).

(7) The time and resources required to collect, collate, standardise and assess historical abundance data for widely distributed species (Meylan \& Donnelly 1999, Seminoff 2004a, Mortimer \& Donnelly 2008) are simply formidable. As are the challenges of standardising recent survey results, even if many are outdated. Independently reviewing such global assessments, checking all references, is rarely done. If, in the end, the effort contributes little to solving species conservation problems per se and is more of academic than practical value, there is an element of futility about the whole exercise (Seminoff \& Shanker 2008).

The confusion created by the Red List emphasising historical abundance over current trends was evidenced at 2 CITES Dialogue Meetings (2001 and 2002) on Eretmochelys imbricata in the Caribbean. Draft IUCN information papers on status (Meylan 2001, 2002) presented clear data indicating positive population trends (Table 1), then proceeded to downplay the obvious conclusions and embellish the view that $E$. imbricata were really critically endangered (as against being classified as such by the Red List) because of scattered insights into historical abundance. This confusion was overcome in the official final information paper (CITES 2002), which superseded the early draft reports and recognised the accuracy problem: that an $80+\%$ decline in 3 generations per se had little bearing on risk of extinction. 


\section{PRECISION AND BIAS IN ASSESSMENTS}

Through standardisation of process, the aims of the new criteria were to improve the precision of assessments (reduce variability) and to increase the accuracy of assessments by reducing biases. Yet precision remains a significant problem (Regan et al. 2005) because among other things, the criteria provide no real guidance on the use of inference (Regan et al. 2005). As a consequence, there remains wide latitude for assessments to be both biased and inaccurate. So it is not altogether clear whether either of these goals has really been achieved.

In the 1996 assessment of Eretmochelys imbricata it was claimed that in addition to meeting the criteria for a past decline, the species also met the criteria for a future decline of $80 \%$ in the next 3 generations (Criteria A2 in Version 2.3). The future decline was dismissed by the SPWG as not being justified on the evidence available at that time (e.g. Table 1)(IUCN 2007b). The procedure's ability to lead to a conclusion like this indicates just how imprecise and subject to bias it remains (Regan et al. 2005).

In addition to problems associated with inference (Regan et al. 2005), omission of data by assessors is an obvious area of concern. According to Meylan \& Donnelly (1999), who provided the hindsight justification for the 1996 Eretmochelys imbricata assessment, the Cuban population of E. imbricata was ignored in 1996 because of 'insufficient information.' The Caribbean population as a whole was estimated to contain $<5000$ nesting females (Meylan 1989), yet Cuba was sustaining an annual harvest of around 5000 larger E. imbriCata $\mathrm{yr}^{-1}$ itself (Doi et al. 1992, Heppell et al. 1995, Heppell \& Crowder 1996, Carrillo et al. 1998b). The assessors were well aware of this harvest because MTSG numbers were modelling the Cuban harvest data.

The most recent assessment of Eretmochelys imbricata status for the Red List (Mortimer \& Donnelly 2008) has again relied on the decline criteria and has again concluded that the global population of $E$. imbricata meets the criteria for critically endangered. Given an underlying view by the assessors that $E$. imbricata cannot biologically sustain harvests (Mortimer et al. 2007), which is not well based in science or logic (Godfrey et al. 2007), this conclusion is perhaps not surprising. Yet once again the unique and important insights gained from Cuba's E. imbricata harvest program (Carrillo et al. 1998a,b,c, 1999) have been largely ignored, as have the conclusions from the official final information paper of the Dialogue Meeting (CITES 2002), which superseded the draft reports quoted as evidence. But this time, the broader MTSG membership has accepted that, despite E. imbricata nominally meeting the Red List decline criteria for critically endangered, it is not critically endangered and, as such, the result is scientifically unjustified. Indeed, Godfrey \& Godley (2008) and Seminoff \& Shanker (2008) have both now advised that no further assessments of marine turtles for the Red List should be undertaken by the MTSG until the problem of accuracy is rectified.

\section{CONSTRAINTS ON CHANGE}

The technical question as to what form of revision to the Red List Criteria is required to improve accuracy remains elusive. Whatever the solution, it will need to be politically acceptable within the complex conservation context of the IUCN and it will need to be sensitive to the multiple roles the Red List plays. Some of the obvious constraints are:

(1) There is an increasing commitment of the Red List to tracking the status of all listed species over time (IUCN 2007a), thereby providing new products at the biodiversity level to meet a new, growing market for such information. At this level of resolution, inaccuracies at the species level are collateral damage. If species assessments are consistently inaccurate over time they may not greatly affect mean trends in biodiversity status. Any fundamental changes proposed to the Red List Criteria, which threaten the foundation stones upon which biodiversity assessments are being built, are likely to be opposed. This is despite concerns that assessment at the biodiversity level, although helpful for defining problems, may not be able to provide effective conservation solutions (Kozlowski 2008).

(2) The power and effectiveness of species level assessments by the Red List, as tools for stimulating grassroots conservation action, is well-established and unlikely to be given up lightly.

(3) It is unlikely that regional species assessments, despite their superficial appeal, will solve the problem of accuracy at the species level. Regional assessments will increase the workload enormously, but still have to deal with the problem of highly variable status within regions (Godfrey \& Godley 2008, Seminoff \& Shanker 2008). Regional assessments challenge the historical focus of the Red List on global extinction.

(4) NGOs and others using the endangered status of wild species to raise funds for conservation and even research, may not support changes to the Red List criteria (scientifically justified or not), that threaten the ability of high profile 'endangered' species, such as marine turtles to find a place in the IUCN Red List. 


\section{A WAY FORWARD}

Seminoff \& Shanker (2008) have provided a detailed assessment of more rigorous approaches for assessing the extinction risks of marine turtles that are arguably better grounded in science and which could form a more objective basis for prioritising conservation action. While strongly supporting their views and recognising the obvious utility of such processes, it is not altogether clear that they would rest comfortably with the importance of the Red List being able to commmit to determinations even when the available data are scant and the quality is poor.

Identifying species threatened with global extinction and thereby establishing credible global conservation priorities is arguably the hallmark of the IUCN Red List. That the Red List process itself has been diverted into quantifying trends in biodiversity conservation complicates the simplicity and strength of its original species focus. That terms such as critically endangered lose their commonsense meaning is not afforded the significance it deserves. In reality, none of the world's marine turtle species may be truly threatened with global extinction (the last individuals dying) today and so their inclusion in the Red List may well have been problematic from the start.

This being so, there is an obvious need for the accuracy of Red List determinations to be improved, which will depend on the criteria being altered, which in turn will require compromises on the part of all players. The decline criteria are the obvious starting point for review. They have obvious biological significance, because extinction must be preceded by decline. Yet as they are the primary criteria used to list commercially harvested species on the Red List, scientific challenges to the accuracy of the Red List assessments based on decline should be expected to increase rather than decrease in the future. Like marine turtles, few marine fisheries species are truly threatened with biological extinction through decline, but the majority are overexploited and threatened with commercial extinction. Most are in urgent need of conservation and management action. The only mechanism the IUCN Red List has for drawing attention to such species is to claim they are in danger of biological extinction globally, even if it is patently untrue and in error.

The only objective, and some might say honourable, way of extricating the IUCN and its Red List from this dilemma is for the Red List to include a category of threat such as 'critically declined.' This would diverge from the historical focus (restriction) on global extinction, but it would remove the main scientific impediment to the current misuse of the decline criteria. That is, data on decline would be used to draw conclusions about decline.
The assignment of a species to 'critically declined' should trigger a separate process, defined in additional criteria, in which the consequences of that decline in terms of global extinction could be assessed. This second process would prioritise population trends from recent scientific surveys. It is relatively easy and costeffective to determine if realistic scenarios exist through which global extinction, the loss of the last individuals in the total global population, is biologically or economically feasible in the short- or long term. If it is, then critically declined species can be reallocated back to whichever of the current defined categories of extinction risk best match its risks. If secondary assessment fails to identify obvious scenarios for global extinction, perhaps because of effective conservation action in parts of a species' range, or where commercial extinction stops the harvesting of a depleted population at levels well above biological extinction, then critically declined as a category in its own right would surely be a more transparent, informative and logical classification than 'near threatened' or 'conservation dependent.'

'Critically declined,' as a statement from the IUCN about the status any species, would be a powerful statement in the hands of advocates demanding conservation action. It would also be a clear and much more incontestable statement of the conservation problems with commercially exploited species. More important, it would open the door for the Red List to play a more effective role in addressing the major conservation and humanitarian challenges linked to resources being depleted at an alarming rate, without having to use risk of global extinction as the gatekeeper or some form of Trojan Horse. Such a category would automatically ensure that a place in the Red List existed for species such as marine turtles, where the major problem is decline and not global extinction.

To do this, the current decline criteria (Criteria A) would not need to be changed, but some species would need to be assigned to critically declined, perhaps annotated with some basic quantification (>90\%, 50 to $70 \%, 30$ to $50 \%, 10$ to $30 \%$ ). As this would be a first stage response, the pressure to allocate vast resources to detailed and defensible assessments of historical abundance, which are arguably needed if trying to use decline data to assess 'extinction risk' in one step would no longer be necessary. Thus, it would open the door for more rapid assessment in the first instance, based on observed, estimated, inferred or suspected declines.

The essence of the approach suggested here is based in fundamental science and problem solving. The problems of defining population depletion should be addressed with data on population decline. The prob- 
lems associated with extinction risk need to be addressed with information on the multitude of factors likely to cause extinction, including historical decline, current trends and numerous other non-biological variables. It would thus overcome the mounting scientific concern about the current system, which is based on the assumption that extinction risk can be predicted from decline alone. Although a tedious task, given the assessments already done to date, SGs could rapidly reassess species previously allocated to extinction risk categories on the basis of the decline criteria, so that the historical database for biodiversity assessment could be corrected.

\section{CONCLUSION}

The IUCN Red List is the most influential international call to action for global wildlife conservation that exists in the world today. Maintaining the credibility of the IUCN Red List and of the IUCN, SSC and SGs, is a conservation priority in its own right. The thousands of scientists who volunteer their services to the IUCN, through the SSC and SGs, cannot be expected to continue doing so if the credibility of the Red List declines in their fields of scientific expertise. The role the Red List plays in identifying species threatened with global extinction is critically important, but is undermined by accuracy problems. Terms such as 'critically endangered' should not be applied to species that have declined by $80+\%$, but that are still abundant and well-buffered from global extinction. The role the Red List plays in biodiversity assessment will no doubt increase, but it should not be at the expense of accuracy at the species level, where pragmatic conservation benefits are achieved. The role the IUCN and Red List play in sustainable resource management needs to be increased, to meet expectations and needs in the 21st century. To do this, the Red List must unfetter itself from the restrictions of global extinction. A 'critically declined' category would recognise population depletion as the critically important conservation and humanitarian problem that it is. By taking such a path, the IUCN, through the Red List, may find itself better positioned to contribute to the conservation of nature and natural resources, and to do so in a way that is firmly based in science. As these appear to be the original goals of the IUCN and Red List, back to basics may be the way forward.

Acknowledgements. The impetus for this paper came from discussions within the IUCN-SSC MTSG after Mortimer \& Donnelly (2008) concluded that the global population of hawksbill turtles in 2007 still met the IUCN Red List Criteria for being considered critically endangered. It stimulated widespread concern amongst MTSG members about the assessments being inaccurate and prompted an array of suggestions about how improvements could be made. It seemed to me that people were assuming the Red List Criteria could be changed easily to correct an obvious problem, when this is clearly not the case. In addressing the subject here, I hope it helps others move forward. I obviously take full responsibility for all errors on the one hand, but thank those who in various ways, perhaps without knowing, have helped shape the ideas contained within: A. Broderick, L. Campbell, M. Godfrey, B. Godley, H. Jenkins, Y. Kaneko, C. Manolis, F. Moncada, N. Mrosovsky, N. Pilcher, J. Seminoff and K. Shanker. Comments by C. Manolis and journal reviewers were most helpful. My involvement with marine turtles over the last 13 years would not have occurred without the vision and strategic charm of the late E. Carrillo, who of course is still very sadly missed.

\section{LITERATURE CITED}

Baillie J, Groombridge B (eds) (1996) 1996 IUCN Red List of threatened animals. IUCN, Gland

Brackett D (2004) Preface. In: 2004 IUCN Red List of threatened species. IUCN, Gland

Broderick AC, Frauenstein R, Glen F, Hays GC and others (2006) Are green turtles globally endangered? Glob Ecol Biogeogr 15:21-26

Brown JH, Lomolino MV (1998) Biogeography. Sinauer Press, Sunderland, MA

Carrillo EC, Perez CP, Moncada FG, Nodarse GA, Rodriguez AM, Meneses A, Manolis SC (1998a) Annex 9. Management program and procedures - traditional wild harvest. Rev Cubana Invest Pesq 22:154-156

Carrillo EC, Moncada FG, Elizalde SR, Nodarse GA, Perez CP, Rodriguez AM (1998b) Annex 4. Historical harvest, trade and sampling data. Rev Cubana Invest Pesq 22: $75-88$

Carrillo EC, Perez CP, Ohtaishi N, Kobayashii M and others (1998c) Annex 7. Population size. Rev Cubana Invest Pesq 22:126-134

Carrillo E, Webb GJW, Manolis SC (1999) Hawksbill turtles (Eretmochelys imbricata) in Cuba: an assessment of the historical harvest and its impacts. Chelonian Conserv Biol 3:264-280

CITES (Convention on International Trade in Endangered Species of Wild Fauna and Flora) (2002) Hawksbill turtles in the Caribbean: basic biological characteristics and population status. Official report from the CITES Dialogue Meetings on E. imbricata presented at CITES COP12, Santiago, Chile. www.cites.org/eng/prog/HBT/intro.shtml

CITES (2008) CITES trade database. www.unep-wcmc.org/ citestrade

Cooney R (2004) The precautionary principle in biodiversity conservation and natural resource management: an issues paper for policy-makers, researchers and practitioners. IUCN, Gland

Doi T, Márquez R, Kimoto H, Azeno N (1992) Diagnosis and conservation of the hawksbill turtle population in the Cuban Archipelago. Japan Bekko Association, Tokyo

Fleming EH (2001) Swimming against the tide: recent surveys of exploitation, trade, and management of marine turtles in the northern Caribbean. TRAFFIC North America, Washington, DC

Fosdick P, Fosdick S (1994) Last chance lost? IS Naylor, New York 
Godfrey MH, Godley BJ (2008) Seeing past the red - flawed IUCN global listings for sea turtles. Endang Species Res 6:155-159

Godfrey MH, Webb GJW, Manolis C, Mrosovsky N (2007) Hawksbill sea turtles: can phylogenetics inform harvesting? Mol Ecol 16:3511-3515

Groombridge B (ed) (1992) Global biodiversity: status of the earth's living resources. Chapman \& Hall, London

Groombridge B, Luxmoore R (1989) The green turtle and hawksbill (Reptilia: Cheloniidae): world status, exploitation and trade. CITES, Lausanne

Heppell SS, Crowder LB (1996) Analysis of a fisheries model for harvest of hawksbill sea turtles (Eretmochelys imbricata). Conserv Biol 10:874-880

Heppell S, Crowder L, Priddy J (1995) Evaluation of a fisheries model for the harvest of hawksbill sea turtles Eretmochelys imbricata in Cuba. US Dept. Commerce, NOAA Tech Memo NMFS-OPR-5

Hutton J, Webb G (2002) Legal trade snaps back. In: Crocodiles. Proc 16th working meeting IUCN-SSC Crocodile Specialist Group. IUCN, Gland, p 1-10

Hutton J, Webb GJW (2003) Crocodiles: legal trade snaps back. In: Oldfield S (ed) Trade in wildlife: regulation for conservation. Earthscan Publications, London

Hutton J, Ross P, Webb G (2002) A review: using the market to create incentives for the sustainable use of crocodilians. In: Crocodiles. Proc 16th working meeting IUCN-SSC Crocodile Specialist Group. IUCN, Gland, p 382-399

IUCN (International Union for Conservation of Nature) (1993) Draft IUCN red list categories. IUCN, Gland

IUCN (1994) 1994 Categories and criteria (version 2.3). www. iucnredlist.org/info/categories_criteria1994\#definitions

IUCN (1995) A global strategy for the conservation of marine turtles. IUCN, Gland

IUCN (2001) IUCN Red List categories and criteria version 3.1. IUCN, Gland

IUCN (2007a) The IUCN Species Survival Commission 2007 IUCN Red List of threatened species. IUCN, Gland

IUCN (2007b) The IUCN Red List petitions process. http://cms.iucn.org/about/work/programmes/species/red_ list/resources/technical_documents/petitions/index.cfm

IUCN/SSC Criteria Review Working Group (1999) IUCN Red List criteria review provisional report: draft of the proposed changes and recommendations. Species 31-32: 43-57

Kozlowski G (2008) Is the global conservation status assessment of a threatened taxon a utopia? Biodivers Conserv $17: 445-448$

Lapointe E (1997) No red alert over conservation red lists. Nature 389:904

Mace GM, Landy R (1991) Assessing extinction threats: toward a re-evaluation of IUCN threatened species categories. Conserv Biol 5:148-157

Mace GM, Stuart SN (1994) Draft IUCN Red List categories, version 2.2. Species 21-22:13-24

Mace G, Collar N, Cooke J, Gaston K and others (1992) The development of new criteria for listing species on the IUCN Red List. Species 19:16-22

Meylan A (1989) Status report of the hawksbill turtle. In: Ogren L (ed) Proc 2nd Western Atlantic Turtle Symposium. NOAA, Panama City, FL

Meylan A (2001) Global status review of the hawksbill turtle (Eretmochelys imbricata) with an emphasis on the wider Caribbean Sea. Draft report presented at the First CITES Wider Caribbean Hawksbill Turtle Dialogue Meeting, Mexico City, 13-17 May 2001 CITES, Geneva

Meylan AB (2002) Global status review of the hawksbill turtle
(Eretmochelys imbricata), with an emphasis on the wider Caribbean. An Addendum for the draft report submitted to the Second CITES Wider Caribbean Hawksbill Turtle Dialogue Meeting, Cayman Islands, 21-23 May 2002 CITES, Geneva

Meylan AB, Donnelly M (1999) Status justification for the listing of the hawksbill turtle (Eretmochelys imbricata) as critically endangered on the 1996 IUCN Red List of threatened animals. Chelonian Conserv Biol 3:201-224

Miller RM, Rodriquez JP, Aniskowicz-Fowler T, Banbaradeniya $\mathrm{C}$ and others (2007) National threatened species listing based on IUCN Criteria and regional guidelines: current status and future perspectives. Conserv Biol 21:684-696

Milliken T, Tokunaga H (1987) The Japanese sea turtle trade 1970-1986. TRAFFIC, Japan

Mortimer JA, Donnelly M (2008) Hawksbill turtle Eretmochelys imbricata. Marine Turtle Specialist Group 2008 IUCN Red List status assessment. www.iucnredlist. org/details/8005

> Mortimer JA, Meylan PA, Donnelly M (2007) Whose turtles are they, anyway? Mol Ecol 16:17-18

Mrosovsky N (1983) Conserving sea turtles. British Herpetological Society, London

Mrosovsky N (1997) IUCN's credibility critically endangered. Nature 389:436

Mrosovsky N (1998) Plight of hawksbill turtles. Nature 392: 646

Mrosovsky N (2000) Sustainable use of hawksbill turtles: contemporary issues in conservation. Northern Territory University, Darwin

Mrosovsky N (2002) Hype. Mar Turtle Newsl 96:1-4

Mrosovsky N (2003) Predicting extinction: fundamental flaws in the IUCN's Red List system exemplified by the case of sea turtles. http://members.seaturtle.org/mrosovsky

NOAA (1999) Coral health and monitoring program. http://coral.aoml.noaa.gov

Possingham HP, Andelman SJ, Burgman MA, Medellin RA, Master LL, Keith DA (2002) Limits to the use of threatened species lists. Trends Ecol Evol 17:503-508

Rabb G (1996) Foreword. In: 1996 IUCN Red List of threatened animals. IUCN, Gland, p 6

Regan TJ, Burgman MA, McCarthy MA, Master LL, Keith DA, Mace GM, Andelman SJ (2005) The consistency of extinction risk classification protocols. Conserv Biol 19: 1969-1977

Rice JC, Legacé E (2007) When control rules collide: a comparison of fisheries management reference points and IUCN criteria for assessing risk of extinction. ICES J Mar Science Advance Access Publ:1-5

ROC (Republic of Cuba) (1998) Transferencia con nota aclaratoria de la población Cubana de tortugas de carey (Eretmochelys imbricata) del apéndice I al apéndice II de la CITES. Rev Cuba Investig Pesq 22:1-58

ROC (Republic of Cuba) (2000) Transferencia con nota aclaratoria de la población Cubana de tortugas de carey (Eretmochelys imbricata) del apéndice I al apéndice II de la CITES. Proposal to CITES COP10, Nairobi

Ross JP (1998) Crocodiles. Status survey and conservation action plan. IUCN, Gland

Salzman L (1995) Scientists and advocacy. Conserv Biol 9: 709-710

Scott P, Burton JA, Fitter R (1987) Red data books: the historical background. In: Fitter R, Fitter $M$ (eds) The road to extinction. IUCN, Gland, p 1-5

Seminoff JA (2004a) MTSG global assessment of green turtles (Chelonia mydas) for the IUCN red list. IUCN Species Survival Commission, April 2004. www.iucn-mtsg.org/ 
red_list/cm/MTSG_Chelonia_mydas_Assessment_April2004.pdf

Seminoff JA (2004b) Guest editorial: sea turtles, red listing, and the need for regional assessments. Mar Turtle Newsl 106:4-6

Seminoff JA, Shanker K (2008) marine turtles and IUCN Red Listing: A review of the process, the pitfalls, and novel assessment approaches. J Exp Mar Biol Ecol 356:52-68

Shrader-Frechette KS, McCoy ED (1999) Molecular systematics, ethics, and biological decision-making under uncertainty. Conserv Biol 13:1008-1012

Spalding MD, Ravilious C, Green EP (2001) World atlas of coral reefs. University of California, Berkeley, in association with UNEP-WCMC

Webb GJW (2000) Are all species equal? A comparative assessment. In: Hutton J, Dickson B (eds) Endangered

Editorial responsibility: Brendan Godley,

University of Exeter, Cornwall Campus, UK species threatened convention. Earthscan Publications, London, p 98-106

Webb GJW (2002) Conservation and sustainable use of wildlife - an evolving concept. Pac Conserv Biol 8:12-26

Webb GJW, Carrillo EC (2000) Role of extinction and categories of endangerment: perspectives from long-lived reptiles. Popul Ecol 42:11-17

Webb GJW, Manolis SC (2002) Cuba and COP12. http://wmi.com.au/wmi-abst.html

Webb GJW, Manolis SC, Whitehead PJ, Letts GA (1984) A proposal for the transfer of the Australian population of Crocodylus porosus Schneider (1801), from Appendix I to Appendix II of C.I.T.E.S. Conservation Commission of the Northern Territory, Darwin

Wilson EO (1992) The diversity of life. Belknap Press, Cambridge

Submitted: March 27, 2008; Accepted: July 24, 2008

Proofs received from author(s): October 12, 2008 